\title{
Servicio y deservicio a Felipe IV. Los Príncipes de Carignano, entre Francia y la Monarquía Hispánica (1634-1644)*
}

\author{
Alejandra Franganillo Álvarez ${ }^{1}$ \\ Escuela Española de Historia y Arqueología en Roma \\ a.franganillo@eehar.csic.es
}

RESUMEN: El propósito de este trabajo consiste en analizar la interesante figura de los príncipes de Carignano, Tomás de Saboya y María de Borbón. Naturales y vasallos de Saboya y Francia respectivamente, el matrimonio estableció un tratado de protección con la monarquía de Felipe IV que la princesa se encargó de gestionar. No obstante, durante los años en los que María de Borbón residió en Madrid, mantuvo una tensa relación con el conde duque de Olivares, al mismo tiempo que Tomás inició conversaciones con la Francia enemiga. La abundante documentación derivada de este suceso nos ha permitido reflexionar sobre el poder de los príncipes italianos en un contexto adverso para la Monarquía, permitiéndoles forzar los límites tradicionales establecidos a la hora de fijar posibles recompensas por el servicio prestado al rey católico. La Corona se resintió por el daño que la defección del príncipe significó para las armas españolas, pues el abandono del servicio a Felipe IV fue seguido del abrazo a la cau-

* Este estudio se ha realizado en el marco del proyecto I+D «Asimilaciones e integraciones de las nuevas noblezas en la Monarquía Hispánica: poder y representación (16211715)», HAR2012-39016-C04-01, financiado por el Ministerio de Economía, Industria y Competitividad y dirigido por Carmen Sanz Ayán. Una primera versión fue presentada en el seminario «Tiempo de Debate», celebrado en el Dpto. de Historia Moderna de la UCM. Agradezco los comentarios y preguntas de los asistentes, especialmente los realizados por Antonio Terrasa Lozano. Asimismo, me siento en deuda con las sugerencias de Rafael Valladares, José Miguel Escribano, Antonio López Anguita y Javier Álvarez García, pues han contribuido a mejorar este trabajo. Las fuentes empleadas en este artículo han sido localizadas en los siguientes archivos y bibliotecas: Archivo General de Simancas (AGS); Archivo Histórico Nacional (AHN); Archive du Ministère des Affaires Étrangères de France (AMAE); Archivio di Stato di Firenze (ASF); Archivio di Stato di Torino (ASTo); Biblioteca Nacional de España (BNE); Bibliothèque Nationale de France (BNF).

ORCID iD: http://orcid.org/0000-0002-5185-4394. 
sa del rey cristianísimo Luis XIII. Y todo ello en un momento muy delicado para la Monarquía española, que ya daba muestras de la futura pérdida de hegemonía europea.

\section{Palabras Clave: Príncipes de Carignano; Felipe IV; Monarquía Hispánica; Negociación; Servicio al rey; Aristocra- cia italiana.}

\section{Service and Unservice to Philip IV. The Princes of Carignano, between France and the Spanish Monarchy (1634-1644)}

ABSTRACT: The main goal of this paper is to examine the fascinating figure of the Princes of Carignano, Thomas of Savoy and Maria of Bourbon. The couple, who were natives and vassals of Savoy and France, signed a protection treaty with the Spanish Monarchy. This treaty was managed by the princess during the time she was living at the Spanish Court. Nevertheless, during the years that the princess stayed in Madrid, she maintained a tense relationship with the Count-duke of Olivares, while Thomas was negotiating with France. The extraordinary amount of sources emanating by this event has allowed us to ponder about the power of the Italian Princes in a difficult time for the Spanish Monarchy. As a consequence, the Princes were able to magnify the rewards that they achieved by serving the King. Even more serious was the impact that the Crown suffered when the prince left the Spanish army and embraced the French alliance. This episode threatened the Spanish hegemony of Europe, and shows the possibilities that France offered to this Italian Princes, especially after 1635.

\section{KEY WORDS: Princes of Carignano; Philip IV of Spain; Spanish Monarchy; King's service; Italian aristocracy.}

CÓMO CITAR ESTE ARTÍCULO/CITATION: Franganillo Álvarez, Alejandra, «Servicio y deservicio a Felipe IV. Los Príncipes de Carignano, entre Francia y la Monarquía Hispánica (1634-1644)», Hispania, 77/255 (Madrid, 2017): 91-115. doi: 10.3989/hispania.2017.004.

Confieso a Vuestra Magestad que totalmente salgo de mí en habiendo de tratar de los negocios desta señora, porque no es posible que aya nacido otra condición igual a la suya ni en Francia ni en ninguna otra parte, y no ay más que decir que después que llegó a España no haziéndose al punto todo quanto ella quiere no se oye otra cosa que amenazas i desafueros tan sin tino que confieso a Vuestra Magestad que es menester mucha ayuda de Dios para poderlo tolerar ${ }^{2}$.

2 Carta del conde duque de Olivares al rey, 19 de octubre de 1637, AGS, Estado Francia, leg. K-1418, $\mathrm{n}^{\circ} 113$. La historiografía ha perpetuado la mala opinión que los coetáneos de la princesa tenían de ella: «I contemporanei e gli storici concordano nel sostenere che la madre di Emanuele Filiberto aveva un temperamento impetuoso e irascibile, amava le feste, i 
Con estas palabras impregnadas de profunda desesperación — exagerada, a tenor del carácter dramático del que gustaba hacer gala al conde duque de Olivares-, el todavía poderoso valido se refería a la princesa de Carignano, quien dejaría en Madrid un amargo recuerdo. En las siguientes páginas desarrollaremos las peculiaridades de la inestable relación que Tomás de Saboya y María de Borbón, príncipes de Carignano, mantuvieron con el cuarto Felipe.

Tommaso Francesco de Saboya (1596-1656) ${ }^{3}$ fue el último hijo varón que tuvieron los duques de Saboya, Carlos Manuel I y Catalina Micaela de Austria. Por sus venas corría doblemente sangre regia, pues a través de su madre era nieto de Felipe II, y descendiente de Francisco I de Francia por vía paterna. Desde muy joven, Tomás destacó por su brillante actuación en el campo militar, siguiendo la estela de su padre ${ }^{4}$. En enero de 1625 Carlos Manuel I concertó el matrimonio de su vástago menor con María de Borbón Soissons, hija del conde de Soissons Carlos de Borbón — primo del rey Enrique IV—; y de la condesa Ana de Montafia y de Clermont ${ }^{5}$. A partir de este momento, la nueva pareja recibió el título de príncipes de Carignano, naciendo así una rama independiente de la Casa de Saboya.

Tras permanecer en París como rehén — consecuencia de la firma de la paz de Cherasco en la que Francia resultó vencedora- Tomás regresó a Turín ${ }^{6}$. Allí comenzó a ver con preocupación la excesiva influencia francesa, de la cual trató de alertar a su hermano el duque Víctor Amadeo I — que había su-

balli e la vita mondana, era orgogliosa delle sue origini francesi, della sua parentela con Luigi XIV e non si adattava alla essenzialità delle Corti sabaude [...]». Cfra. PICCO, 2010: 3.

3 Véase la biografía centrada en su labor militar que le dedicó QUAZZA, 1941 y SCLOPIS, 1832. Sobre su enfrentamiento con Cristina de Francia: CLARETTA, 1869: 342 y ss. La visión de este autor es favorable a la duquesa, juzgando negativamente la actuación de Tomás y de Mauricio. RAVIOLA, 1 (Madrid, 2014): 250. Destacamos el estudio reciente que le ha dedicado SPAGNOLETTI, 2015.

4 Para profundizar en la fascinante figura del duque Carlos Manuel I, nos remitimos a MERLIN, 1991. MASOERO, MAMINO e ROSSO, 1999. Una síntesis de la dinastía piamontesa hasta al guerra civil la ofrece MERLOTTI, 2006.

5 Entre los enemigos del cardenal Richelieu con los que la Corona mantuvo contacto se hallaba el conde de Soissons, a quien Felipe IV se comprometió a proteger: Capitulos concertados entre la Reyna cristianísima Madre y el sereníssimo cardenal Infante de España para procurar el bien común de las coronas en virtud del poder que para ello tiene de su Magestad Católica, 22 de mayo de 1637. AMAE, Correspondance Politique, Espagne, vol. 18, fol. 486. El conde había participado, junto al príncipe de Condé y la duquesa de Chevreuse, en la conspiración de Chalais (1626), DUBOST, 2011: 693-696.

6 La Paz de Cherasco (1631) puso fin a la Segunda Guerra del Monferrato, iniciada en 1627 tras la muerte de Vicente II de Mantua. La Monarquía Hispánica intervino militarmente para impedir la sucesión del duque de Nevers, lo que desembocó en el fracaso del asedio de Casale en marzo de 1629. Sobre el duque de Nevers véase PARROT, 1997. Para profundizar en el desarrollo de la guerra y sus consecuencias en el ducado de Saboya, destacamos el trabajo de OSBORNE, 2002: 144-172. 
cedido a padre en julio de 1630 - , sugiriéndole un acercamiento a la Monarquía Hispánica 7 . Desoyendo sus consejos, en 1634 el duque de Saboya le propuso que fuese su representante plenipotenciario en la corte francesa. Sin embargo, Tomás rechazó la propuesta y huyó a Flandes para ofrecer sus servicios a Felipe IV ${ }^{8}$. Una vez allí, el de Carignano fue designado capitán de las tropas españolas en Flandes bajo las órdenes del entonces gobernador, el cardenal-infante don Fernando 9 . Los hombres que configuraban el órgano gubernativo residente en Madrid eran conscientes del enorme valor de Tomás, dada su amplia y probada experiencia al mando del ejército saboyano ${ }^{10}$.

Cuando el príncipe entró al servicio de la Monarquía Hispánica en 1634, la princesa de Carignano se trasladó a Milán, hasta que en enero de 1636 solicitó ayuda a Felipe IV para viajar a la corte ${ }^{11}$. El 26 de julio María de Borbón y sus cinco hijos desembarcaban en Barcelona, y a mediados de septiembre iniciaron su jornada a Madrid ${ }^{12}$. La francesa escribió al rey y a la reina Isabel de Borbón reiterándoles que nunca olvidaría los favores que le habían brindado a su marido, a ella y a sus hijos, a los que correspondería con «toda suerte de muy humilde servicio y obediencia» ${ }^{13}$. Su llegada fue celebrada el $16 \mathrm{de}$

7 A comienzos de 1630 existían en la corte de Turín dos grupos: uno pro-francés, encabezado por Cristina de Francia y Víctor Amadeo; y el filoespañol, integrado por Margarita, Tomás y Mauricio de Saboya. GINARTE GONZÁLEZ, 49/172 (Madrid, 1989): 735.

8 En esta decisión también influyó el nacimiento en junio de 1634 del segundo hijo varón de los duques de Saboya -el futuro Carlo Emanuele II- lo que alejaba aún más a Tomás de la sucesión al ducado. ORESKO, 1997: 286-287. OSBORNE, 2002: 238. El 23 de febrero el cardenal-infante comunicó a Felipe IV la intención de Tomás y su esposa de entrar a su servicio. Carta del Cardenal-infante al rey, 23 de febrero de 1634, AGS, Estado Italia, leg. 3341, nº 84.

9 Las cuestiones relativas al nombramiento del cardenal-infante han sido tratadas en ESTEBAN ESTRÍNGANA, 2015, vol. 3.

10 Así lo reconoció el cardenal-infante: «es hombre de bien en lo personal, valiente y soldado, porque aviéndose criado en las guerras del Piemonte aprendió la disciplina militar de su padre, que en esta parte estimaba mucho su consejo y resolución [...] De las cosas de Francia tiene mucha inteligencia y plática, y si se hubiese de romper la guerra con aquella corona siempre sería de mucho servicio porque no debe de correr bien con el cardenal de Richelieu y deseará la mutación del gobierno como los demás malcontentos». Carta del Cardenal-infante al rey, 23 de febrero de 1634, AGS, Estado Italia, leg. 3341, n 84. El 5 de junio de 1634 Olivares manifestó al príncipe de Carignano su alegría porque hubiese decidido servir a Felipe IV. ASTo, Lettere Principi Diversi, Savoia-Carignano, mazzo 39.

11 En el verano de 1635 Felipe IV escribe a su prima María de Borbón asegurándole el amor que sentía hacia ella y hacia su marido. Copia de carta de Feliep IV a la princesa de Carignano, Madrid, 18 de julio de 1635 (traducida al francés), ASTo, Lettere Principi Forestieri, Spagna, mazzo 98.

12 Los hijos de los príncipes de Carignano que viajaron con María de Borbón fueron: Luisa Cristina (1627-1689); Emanuele Filiberto (1628-1709); Giuseppe Emanuele (16311656) y Eugenio Maurizio (1635-1673). Durante su estancia en la península nacería su último hijo Ferdinando, que murió el mismo día (16 de julio de 1637). PICCO, 2010: 4.

13 Carta de la princesa de Cariñán al rey, 1634 (traducción), AGS, Estado, leg. 3647, nº 31. 
noviembre de 1636 con espléndidos festejos, coincidentes con la coronación como rey de Romanos de Fernando, monarca de Hungría y consorte de María de Austria, hermana pequeña de Felipe IV ${ }^{14}$. Eran todavía momentos felices, si bien no tardarían en aparecer los primeros conflictos.

\section{Bajo la protección de Felipe IV: las negociaciones entre el Prín- CIPE Y LA CORONA A TRAVÉS DE LA INTERMEDIACIÓN DE SU MUJER}

Una vez asentada en la Corte, la princesa de Carignano debía negociar con la Corona en nombre de su marido la firma de un tratado que estableciese los términos del servicio que prestaría a Felipe IV. Al mismo tiempo, el cardenal Mauricio - hasta entonces al servicio de Luis XIII- solicitó la protección del Emperador ${ }^{15}$. Pese a que la princesa tenía pensado permanecer unas semanas en la Corte y luego partir junto a su esposo, las conversaciones se alargaron primero meses, después años. En diciembre de 1636 el rey manifestaba que no estaba dispuesto a aceptar las excesivas condiciones exigidas por Tomás, entre las que se incluían una asignación pecuniaria fija; la abadía de San Claudio en Borgoña para su hijo Mauricio; el oficio de secretario de la lengua para su secretario personal, y la más importante de todas: el apoyo de su candidatura como titular del Piamonte ${ }^{16}$.

La Junta encargada de tratar estos asuntos recomendaba dilatar lo máximo posible la firma, obligando a la princesa a permanecer en Madrid hasta que finalizase el conflicto con Francia. Como compensación, el cardenal Borja proponía ofrecerle a Tomás el virreinato de Valencia, siempre y cuando la pareja permaneciese separada; en su defecto, recomendaba que dejasen a sus dos vástagos mayores en la Corte ${ }^{17}$. La Corona no reconoció el poder que

14 Véase CARO DE MALLÉN, 1637, BNE, VE/63/5. MÉNDEZ SILVA, 1637, BNE, R/13182. SÁNCHEZ DE ESPEJO, 1637, BNE, R/11693/44. Esta última obra está dedicada a Olivares.

15 Las múltiples fidelidades del cardenal Mauricio han sido analizadas en RAVIOLA, 1 (Madrid, 2014): 244-259.

16 Consulta de la Junta Estado, 19 de diciembre de 1636, AGS, Estado Francia, K-1418, $\mathrm{n}^{\circ} 45$. Véanse las demandas completas en Papel de las cosas que presenta su señora la princesa de Cariñán para entrar en la protección de su Magestad, 21 de noviembre de 1636, Ibidem, $\mathrm{n}^{\mathrm{o}} 3$. El príncipe, en nombre de su esposa, prometía tomar las armas a favor del rey Felipe IV; no establecer ligas con otros reinos; arriesgar la vida si fuese necesario por el rey; avisar de todo lo que pudiese ayudar o dañar al rey. Asimismo, promete fidelidad en nombre de ambos y de sus hijos nacidos y por nacer; y que cuando uno de estos cumpliese doce años, lo enviaría al servicio del príncipe Baltasar Carlos.

17 Consulta de la Junta Estado, 17 de diciembre de 1636, AGS, Estado Francia, K-1418. Anteriormente, el Consejo de Estado había propuesto que el hijo mayor viajase a Portugal para que se emplease en el servicio del rey junto a su tía la virreina Margarita de Saboya. Consulta del Consejo de Estado, 30 de enero de 1636, AGS, Estado Francia, K- 1418, nº 4. 
poseía la francesa, por lo que el príncipe tuvo que elaborar uno nuevo en enero de $1637^{18}$. Por fin, dos años después Tomás ratificaba este tratado, incidiendo en que deseaba emplearse al servicio del rey

Por modo de simple protección y no de sugeción de vasallaje i consiguientemente que la obligación de traer las armas i observar la fidelidad i las otras cosas prometidas se entiende no como de vasallo o hombre sugeto sino como de empleado en el servicio de S.M. i de su real corona, i con condición que dichas armas no se muevan directamente contra la persona i estado de la Alteza de Saboya por no contravenir al juramento prestado como su vasallo i como caballero de la orden de la Anunciata ${ }^{19}$.

No obstante, con la llegada del conflicto civil a Saboya en 1638 y las rebeliones internas a las que deberá enfrentarse la Monarquía Hispánica en la década de 1640, las peticiones del príncipe se vieron alteradas, así como la relación que él, y especialmente su esposa, mantendrán con el monarca y su valido.

\section{La guerra civil en Saboya (1638-1642)}

La muerte el 1 de octubre de 1637 de Víctor Amadeo I trajo como consecuencia la regencia de la hermana de Luis XIII, Cristina de Borbón, dada la minoría de edad de su primogénito Francesco Giacinto. El gobierno de Madama Reale - título adoptado por Cristina - ha sido negativamente juzgado por la historiografía tradicional, acusando a la duquesa de haber delegado sus obligaciones políticas en manos de sus amantes y de Francia ${ }^{20}$. En octubre de 1638 el repentino fallecimiento de Francesco Giacinto convirtió en heredero a su hermano Carlos Manuel — de cuatro años y con una salud delicada-, lo que condujo a un incremento de la inestabilidad en todo el territorio saboyano. Los príncipes Tomás y Mauricio de Saboya se apoyaron en los rumores según los cuales Víctor Amadeo había sido envenenado por los franceses - contando con el beneplácito de la duquesa consorte - para justificar una mayor participación en el gobierno del Piamonte. La falta de entendimiento entre los príncipes Tomás y Mauricio y su cuñada Cristina de Francia desembocó en una guerra civil que enfrentó a los partidarios de la regente por un

18 Copia de la protección del señor Príncipe Thomás y la señora Princesa de Cariñán. AGS, Estado, leg. 3661, n ${ }^{\circ} 70$. El poder original está en AGS, Estado Francia, K-1418, $\mathrm{n}^{\mathrm{0}} 75$.

19 Carta del Príncipe Thomás, 7 de diciembre de 1639, AGS, Estado Italia, leg. 3661, nº 72.

20 La etapa correspondiente a la regencia de Cristina ha sido analizada en diversas obras dedicadas a la historia de la Casa de Saboya, entre ellas CLARETTA, 1869. De los estudios más recientes destacamos los de BÉLY, 2002. ORESKO, 2008. ROSSO, 2008. FERRETTI 1/262 (París, 2014a); 2014b. 
lado, y los de Tomás y Mauricio por otro, bandos que gozarían del apoyo respectivo de Francia y la Monarquía Hispánica ${ }^{21}$.

Inmediatamente después de conocer la muerte de Víctor Amadeo, Tomás envió una carta a su mujer informándole de la necesidad de acudir a Milán para auxiliar el Piamonte, pues la regencia de Cristina y el posicionamiento que su hermano Mauricio adoptaría le tenían muy preocupado. En los planes del príncipe de Carignano su esposa ocupaba un lugar privilegiado: ella debía ejercer como intermediaria ante Felipe IV y Olivares para que le permitiesen abandonar Flandes, si bien el rey católico se resistía a dejarle partir a Milán ${ }^{22}$. El propósito de Tomás y del cardenal Mauricio era apoderarse del mayor número posible de plazas fuertes y forzar la firma de un tratado de paz que mejorase sus respectivas posiciones en el Piamonte, para lo que solicitaron al rey católico y al emperador el envío de tropas. Felipe IV tomó partido por los príncipes Tomás y Mauricio, y desde el inicio de la guerra civil el embajador saboyano abandonó Madrid como manifestación de la ruptura de relaciones. Tras el fallecimiento del duque de Saboya, Cristina escribió a Felipe IV y a su hermana Isabel de Borbón disculpándose por no haberse podido comunicar con ellos libremente, y solicitando su amparo. No obstante, el monarca desconfiaba de las verdaderas intenciones de su cuñada: «estas cartas se tienen por demasiado de buenas». Aun así, la Corona no cerró las puertas a un acercamiento a la regente, asegurándole que intercedería ante Tomás y Mauricio en su favor, siempre y cuando expulsara a los franceses, condición que no cumpliría ${ }^{23}$.

En marzo de 1639 el príncipe de Carignano entró en el Piamonte a la cabeza de un ejército, y gracias al apoyo español inició el asedio a Turín, tomando la ciudadela el 27 de julio de 1639. Después de un breve alto al fuego entre el 14 de agosto y el 14 de octubre de ese año, la intervención de las tropas francesas permitió al bando de Madame Reale iniciar una serie de victorias y recuperar las plazas perdidas, obligando a Tomás a abandonar el asedio y retirarse a Ivrea ${ }^{24}$. La Corona española, inmersa desde 1635 en una guerra contra su principal potencia enemiga, no se hallaba en posición de desviar provisiones. Esto, junto a la mala relación que el príncipe de Carignano man-

21 Para profundizar en la actuación del príncipe Tomás durante el conflicto civil, véase PATRUCCO, 1898. QUAZZA, 1960. OSBORNE, 2002: 258-271.

22 Lettere a la princesse de Carignan, 2 de noviembre de 1637, ASTo, Lettere Principi Diverse, Savoia-Carignano, Mazzo 52.

23 Copia de Carta de la duquesa de Saboya para la reina, Turín, 1 de noviembre de 1637. AGS, Estado Italia, leg. 3661, $\mathrm{n}^{\circ}$ 204. Carta del rey al conde de la Roca 14 de enero de 1638, Ibidem, $\mathrm{n}^{\circ} 143$. El marqués de Leganés escribió al rey el 27 de marzo de 1638 sobre la llegada de un emisario de la duquesa, quien aseguró que «no puede romper con franceses porque será perder Saboya y meter en peligro el Piamonte». AGS, Estado Italia, leg. 3346, nº 173.

24 PATRUCCO, 1898: 37-57. 
tuvo con el marqués de Leganés, constituyó la coartada perfecta para justificar su desafección al monarca hispánico poco tiempo después ${ }^{25}$. A partir de 1640 parecía evidente que el bando de la duquesa regente acabaría obteniendo la victoria, lo que explica que Tomás y Mauricio iniciasen conversaciones secretas con Francia ${ }^{26}$. Dos años antes, el cardenal-infante había escrito a Felipe IV para advertirle de que un sirviente de Tomás estaba intentando que abandonase el servicio a la Monarquía. El sirviente le había asegurado que Richelieu y Olivares habían pactado repartirse Saboya y el Piamonte, algo que - supuestamente - la princesa le corroboró en sus cartas ${ }^{27}$. Al mismo tiempo, Cristina trató de ganarse a María de Borbón a su causa, proponiéndole en junio de 1638 unirse a la liga formada por ella y por Luis XIII para asegurar la legitimidad de su hijo como duque de Saboya ${ }^{28}$. Una vez finalizada la contienda, el 14 de junio de 1642 Cristina, Mauricio y Tomás sellaron su reconciliación. Mauricio abandonó el cardenalato para contraer matrimonio con la hija mayor de Cristina, María Ludovica, y asumió la lugartenencia de Niza; Tomás recibió el mismo título en Ivrea y Biella. Ambos hermanos entraron en el Consejo de regencia, pasando además al servicio de Francia. De hecho, el príncipe de Carignano obtuvo el mando supremo del ejército franco-saboyano en la guerra contra la Monarquía Hispánica.

\section{El principio del fin. Los intentos de huída de la princesa}

Si durante los primeros meses de su estancia en Madrid las actitudes de la princesa se incluyeron dentro de la cortesía esperada, con el paso del tiempo María de Borbón manifestaría en repetidas ocasiones su intención de reconciliarse con Francia, y arrastrar con ella a su marido 29 .

25 El 10 de julio de 1639 Tomás informaba a Felipe IV y a Olivares que para conseguir expulsar a los franceses de Italia y no perder las plazas ocupadas necesitaba 1.000 infantes y otros tantos caballos. ASTo, Lettere Principi Diversi, Savoia-Carignano, mazzo 53.

${ }^{26}$ En el Archivo de Turín se conserva un borrador de carta de Tomás dirigido al marqués de Leganés y fechado el 8 de abril de 1640 en el que reconoce que «todavía se mantienen los tratados con Madama por las conveniencias que se han dicho diferentes vezes, pero no sé cómo entiende que yo quedé mal satisfecho de requerimiento que me hizo de suspenderlos hasta tener respuesta de S.M. y si bien yo no ignoro mi obligación [...] he ido informándole de quanto se ofrece y conviene». ASTo, Lettere Principi Diversi, Savoia-Carignano, mazzo 53.

27 OSBORNE, 2002: 263.

28 Lettre de Chrestienne de France à madama la princesse de Carignan, 15 de juin 1638, BNF, Manuscrits Français, 3842, fol. 54.

29 A lo largo de 1639 el príncipe Tomás había escrito al rey y a Olivares pidiendo que dejasen partir a su mujer. No obstante, los consejeros de Estado estaban preocupados por los rumores según los cuales el de Carignano y su hermano Mauricio estaban en tratos con la duquesa de Saboya. Consultas del Consejo de Estado, 17 de julio de 1639; Cartas del prínci- 
En abril de 1640 María de Borbón se dirigió a Olivares anunciándole su inminente salida, tras llevar años amenazando con hacerlo ${ }^{30}$. Ahora, la posición de la Monarquía había empeorado, pues a la sublevación catalana en junio de 1640 se sumó el levantamiento portugués el primero de diciembre. A esas alturas, la guerra civil de Saboya estaba prácticamente ganada por el bando de Cristina - gracias a la determinante ayuda francesa-, y los hermanos Tomás y Mauricio negociaban con Luis XIII.

En el verano de 1641 Felipe IV había prometido a la princesa que en octubre podría emprender su marcha; hasta entonces, le ofreció alojarse en el cuarto de palacio que había pertenecido al Cardenal-Infante ${ }^{31}$. Como llegada la fecha la situación no cambió, María de Borbón decidió motu proprio emprender su marcha. El rey ordenó al marqués de Castañeda que la detuviese, tratando de convencerla del aprieto en el que podía poner a su marido ${ }^{32}$. Mientras tanto, y tras recibir avisos de las conversaciones que Tomás y Mauricio mantenían con los franceses, Felipe IV envió al conde de Siruela a negociar la firma de un acuerdo: «se procurará daros a vos [el cardenal Mauricio] y al Príncipe Thomas mi primo toda la satisfación que se pudiere», para lo cual ya había ordenado a los virreyes de Nápoles y Sicilia que les pagasen las pensiones que les debía ${ }^{33}$. Unos meses más tarde llegó la respuesta del príncipe Tomás. El de Saboya lamentaba el intento de fuga de su mujer, si bien aclaraba que según la versión que ella misma le había proporcionado, su intención no había sido la de marcharse sin antes despedirse de los monarcas. En cuanto al juramento, recordaba no haber recibido todo lo prometido la primera vez que entró bajo la protección de Felipe IV, y que los 20.000 escu-

pe Tomás a Olivares, 13 de septiembre y 13 de octubre de 1639. AGS, Estado Italia, leg. $3647, \mathrm{n}^{\circ} 176 ; 188 ; 189 ; 193$.

30 Copia (en español) de la carta de la princesa de Carignano a Olivares, 21 de abril de 1640, AGS, Estado Italia, leg. 3648, nº 19. Tres años antes, en 1637, Olivares escribió a la princesa inmediatamente después de enterarse — a través de la reina - de su intención de abandonar Madrid. En esa ocasión le deseaba feliz viaje, si bien le advertía que se lo comunicarían a su marido. Es obvio que la Corona no iba a permitir la salida de María de Borbón, pero por entonces trataban de mantener buenas relaciones con ella. Carta del conde duque de Olivares a la princesa de Carignano, 19 de mayo de 1637, ASTo, Lettere Principi Diversi- Savoia Carignano, Mazzo 56.

31 Carta de Felipe IV a la princesa de Carignano, 4 de agosto de 1641, AGS, Estado Italia, leg. 3853, n 239 (se conserva una copia en ASTo, Lettere Principi Forestieri, Spagna, mazzo 98).

32 Carta de Felipe IV al marqués de Castañeda, 3 de octubre de 1641, AGS, Estado Italia, leg. 3691, no 93.

33 Cartas de Felipe IV al cardenal Mauricio, 1 y 15 de octubre 1641, ASTo, Lettere Principi Forestieri, Spagna, mazzo 98. La fórmula que el conde de Siruela propuso a Tomás implicaba que éste jurase ejercer el cargo de capitán general del ejército, que informase de todo lo que perjudicase los intereses de la Monarquía Hispánica, además de alejarse de «todo lo que no fuere del servicio de su Magestad». AGS, Estado Italia, leg. 3454, n 120; leg. 3649, nº 3. 
dos que ahora le ofrecía no resultaban suficientes ${ }^{34}$. Tres días después el conde de Siruela anunciaba que, según le había asegurado el embajador florentino en Francia, la intención de la princesa había sido salir de Madrid y llegar a Cataluña para pedir allí la protección de Luis XIII. De esta manera, Tomás tendría una excusa para no tomar las armas contra aquella Corona ${ }^{35}$. Por su parte, el conde de la Rivera - comisario general de la caballería del Estado de Milán - consideraba que no estaba todo perdido, pues aunque Tomás estaba en conversaciones con los franceses, éstos no podían ofrecerle la sucesión en el Piamonte, que era lo realmente ambicionaba.

Para conseguir que el de Carignano rompiese definitivamente con Francia la permanencia de su mujer en Madrid resultaba clave, decisión en la que todos los ministros del rey coincidían ${ }^{36}$. No obstante, en septiembre de 1642 Tomás envió un gentilhombre a Madrid para comunicar su adhesión al bando configurado por Cristina y Luis XIII, convirtiéndose así en enemigo de la Monarquía $^{37}$. Por si no fuese suficiente, había ocupado plazas en Milán con el ejército francés, por lo que el Consejo de Estado dilucidaba qué hacer con la princesa y sus hijos, recordando sin embargo que el monarca debía dar pruebas de su grandeza y clemencia ${ }^{38}$. Pese al cambio de bando de Tomás, los consejeros recomendaban proceder con precaución, pues se sospechaba que el príncipe no estaba muy conforme con la actitud de los franceses, existiendo la posibilidad de que regresara al servicio de la Monarquía.

La desesperación de la princesa, unida a su negativa a permanecer más tiempo en Madrid, le llevó a repetir su intento de fuga en la primavera de 1643, meses después de la destitución del conde duque, con el que había tenido numerosos enfrentamientos ${ }^{39}$. Tras muchas deliberaciones, el Consejo de Estado decidió que fuese trasladada a Carabanchel junto con sus hijos, custodiados por un destacamento de soldados. Con la muerte de Luis XIII, la Corona española intensificó las conversaciones con Tomás para que regresara al servicio de Felipe IV; ya en febrero se había barajado la posibilidad de dejar salir a la princesa a cambio de la liberación de Tortona, plaza ubicada en el

34 Copia de carta de Tomás de Carignano al conde de Siruela, diciembre de 1641, AGS, Estado Italia, leg. $3645, \mathrm{n}^{\circ} 7$.

35 Carta del conde de Siruela, diciembre de 1641, AGS, Estado Italia, leg. 3645, $\mathrm{n}^{\circ} 8$.

36 Consulta del Consejo de Estado, 22 de mayo de 1642, AGS, Estado Italia, leg. 3847, nº 93.

37 Consulta del Consejo de Estado, 27 de septiembre de 1642, AGS, Estado Italia, leg. $3662, \mathrm{n}^{\circ} 20$.

38 Se barajó la posibilidad de trasladarlos a la casa de Guadalajara del duque del Infantado y despedir a todos sus criados dejando sólo a las mujeres. Consulta del Consejo de Estado, 30 de octubre de 1642, AGS, Estado Italia, leg. 3662, $\mathrm{n}^{\circ} 30$.

39 Relazione dell'uscita di Spagna della signora principessa di Carignano, ASF, Miscellanea Medicea, 178, cc. 324-337. 
Piamonte ${ }^{40}$. Sin embargo, el de Carignano defendió ante el enviado del rey Gerónimo Vélez de Medrano el tratado que había firmado con Madama Reale, algo a lo que — según él — se había visto obligado por culpa del marqués de Leganés y el conde de Siruela ${ }^{41}$. Lo que Tomás eludía contar era que en 1641 falleció su cuñado el conde de Soissons, y Richelieu le prometió que la princesa heredaría el título y las propiedades a cambio de que mudasen su fidelidad, una tentadora oferta que no podría rechazar.

La de Carignano recibió la esperada licencia para partir de Madrid en marzo de 1644, si bien su marcha se retrasó unos meses más debido a un incidente protagonizado por su primer caballerizo, quien había herido de gravedad en una pelea a otro hombre. Lejos de lamentarse por este suceso, la princesa exigía se castigase al Alcalde Enrique de Salinas por haber enviado a su servidor a una cárcel pública - pues era un caballero-, solicitando su liberación. En sus recriminaciones, la francesa alegaba que su caballerizo no era vasallo de Felipe IV, sino criado de su marido - un príncipe libre - , por lo que el rey no estaba autorizado a ejercer justicia sobre él ${ }^{42}$. Resulta curioso que después de tantos años recomendando que la princesa permaneciese en la Corte, casi todos los consejeros que trataron este nuevo incidente se sintieron aliviados ante su inmediata marcha ${ }^{43}$. No opinaba lo mismo Olivares, quien desde su exilio en Toro consideraba desacertada esta decisión, pues estaba seguro de que Tomás no lo agradecería. Quizás, de haber seguido en el gobierno, el conde duque habría frustrado la ansiada puesta en libertad de la princesa, o al menos la habría retrasado ${ }^{44}$.

40 Los miembros del Consejo de Estado incidían en que no se aludiese explícitamente al intercambio como requisito, pues parecería que el rey había retenido a la princesa con la intención de negociar con su vida. Por ello, proponían que se le concediese la libertad sin relacionarla con el trueque negociando en secreto, pues la recuperación de dicha plaza resultaba crucial ya que permitiría socorrer Milán. Consulta del Consejo de Estado, 18 de febrero de 1643, AGS, Estado Italia, leg. 3662, $\mathrm{n}^{\circ} 45$.

41 Carta de Gerónimo Vélez de Medrano, 5 de marzo de 1643, Ibidem, nº 50.

42 Como gobernadora en ausencia de Felipe IV, Isabel de Borbón mandó constituir una Junta que dictaminó prisión en casa para el caballerizo y reconoció la torpeza del Alcalde, quien fue arrestado unos días. Felipe IV ratificó dicha decisión el 11 de junio. Consulta de la Junta, 3 de junio de 1644, AGS, Estado, leg. 3649, n 86; Carta de la princesa de Carignano a la reina, Ibidem, $\mathrm{n}^{\circ} 98$.

43 Así lo resumió el marqués de Castañeda: «lo que conviene que V.M. se desembaraçe de la Princesa que manifiestamente busca las occasiones para publicarse ofendida y agraviada sin otro fin ni pretensión de otro útil que de occasionar multiplicar materia entre los enemigos de V. Magestad para sus discursos». Consulta de la Junta, 6 de junio de 1644, AGS, Estado Italia, leg. 3649, nº 99.

44 «Mal deben de andar las cosas de Italia pues se ha concedido licencia a la de Cariñán, pero no tengo al marido por hombre de gentilezas y así temo lo agradecerá poco [...]». Carta de Olivares a Antonio Carnero, 9 de marzo de 1644, AHN, Estado, libro 869, fol. 111. Agra- 


\section{El deber del Servicio Versus la felonía del Príncipe de Carignano}

El acuerdo de protección que la Monarquía y el príncipe negociaron buscaba establecer una relación de fidelidad ${ }^{45}$ beneficiosa para ambas partes, pues a cambio de sus servicios, Tomás pretendía obtener una serie de privilegios; entre ellos, que el monarca le financiase un ejército particular. A comienzos de 1640 Felipe IV encargó al marqués de Caracena que vigilase de cerca al de Saboya, lo que indica que ya se sospechaba de su vinculación con Francia ${ }^{46}$.

Anteriormente y de manera sucinta hemos aludido a los problemas surgidos a la hora de ratificar el tratado por ambas partes. Aunque la princesa pisó Madrid en noviembre de 1636, tres años después aún se esperaba que Tomás firmase la escritura de protección. Si al principio fue la Corona la que puso objeciones porque la francesa empezó a exigir beneficios que no habían sido previamente acordados, sería después el turno de su cónyuge, quien no estaba conforme con determinados puntos. En concreto, el príncipe se negó a aceptar aquellos que exigían se comportase como un vasallo y súbdito de Felipe IV, algo que ni era ni tenía intención de ser:

El Príncipe respondió que [...] havía hallado que la forma de la protección era contra su libertad y su reputación a lo qual él no podía consentir, que absolutamente le haçía aquella capitulación hombre ligio, Vasallo y súbdito de Su Magestad de la manera que lo eran los del Piamonte respecto del Duque, y que le querían obligar a faltar a la casa de Saboya y al Imperio [... $]^{47}$.

Lo cierto es que, en realidad, muchas de las objeciones del príncipe no se hallaban en la protección ofrecida por el monarca, la cual mantenía los mismos términos que las establecidas con las Repúblicas de Génova o Lucca. No obstante, Tomás defendía que era incompatible prestar fidelidad a Felipe IV siendo vasallo del duque de Saboya, a lo que desde Madrid se respondía que únicamente se le demandaba la fidelidad típica del protegido al protector ${ }^{48}$. Ahí radica la

dezco la enorme generosidad de Vanessa de Cruz y Javier de Castro por haberme facilitado esta referencia.

45 Sobre el significado y evolución de este concepto en la Monarquía Hispánica, véase VALLADARES RAMÍREZ, 2015.

46 Instrucción al Marqués de Caracena, 26 de febrero de 1640, AGS, Estado Italia, leg. $3661, \mathrm{n}^{\circ} 77 ;$ Instrucción al conde de Siruela, $\mathrm{n}^{\mathrm{o}} 78$.

47 AGS, Estado Italia, leg. 3661, $n^{\circ} 99$.

48 Tomás consideraba que la cláusula que le impedía configurar ligas con otros príncipes implicaba vasallaje, y no estaba dispuesto a tomar las armas en contra de Saboya, algo que sin embargo no aparecía en la escritura. Esto nos hace pensar que él mismo lo inventó para retrasar la firma. A la Corona no le agradó que el príncipe despreciase la posibilidad de convertirse en vasallo. De hecho, recordaba que el rey tenía por feudatarios y vasallos al Gran Duque de 
importancia porque el príncipe firmase el tratado, pues quedarían establecidos los servicios concretos que debía prestar a Felipe IV y las contraprestaciones que recibiría por ellos ${ }^{49}$. Si bien es cierto que finalmente Tomás aceptó las condiciones de dicho tratado, parece que no era la instrucción original que la Corona había enviado, quedando ésta en manos de la princesa, de quien sospecharon pudo haberle mandado a su marido una versión modificada.

Las reticencias de Tomás — que hacían al conde duque desconfiar de sus verdaderas intenciones - manifiestan su necesidad porque no se olvidase su estatus como príncipe libre. En base a este argumento, su mujer protestará cuando Felipe IV se refiera a él como «príncipe rebelde», al considerar que «siendo un Príncipe libre no puede nunca tener este nombre» ${ }^{50}$. Ni el príncipe ni su mujer se consideraban vasallos ni súbditos de Felipe IV, ergo estaban exentos de obedecerle ${ }^{51}$. Tal y como María de Borbón alegó en una carta a Olivares el 21 de abril de 1640, al no ser súbdita no tenía por qué pedir licencia a Felipe IV para acudir junto a su marido, pues únicamente Dios podía separarles $^{52}$. Aun de acuerdo con este hecho, Olivares condenaba que la de Carignano no se hubiese mostrado nunca «agradecida ni satisfecha» ante los numerosos privilegios que ella y su familia había recibido del rey. En una misiva que Felipe IV envía a María de Borbón en julio de 1640, el monarca hacía referencia a la cuestión de la gratitud: «si bien espero de lo que me devéis y a la Reyna no obraréis una expresa desconveniencia de vuestro marido y ingratitud con nosotros» ${ }^{53}$. De la misma manera que era justo que el príncipe recibiese las mercedes prometidas si había servido satisfactoriamente al rey, era también de justicia que mostrase agradecimiento ${ }^{54}$.

Toscana, al duque de Parma y al de Módena. Relación de lo que ha pasado con la Serenísima Princesa de Cariñán, 14 de febrero de 1640, AGS, Estado Italia, leg. 3661, nº 115.

49 Los nobles franceses que brindaron sus servicios a Felipe II firmaron un juramento que les presentaba como súbditos leales sin entrar en contradicción con su naturaleza francesa. RUIZ IBÁÑEZ, 2012: 180.

50 Carta de la Princesa de Carignano a Felipe IV, 30 de octubre de 1642, AGS, Estado Italia, leg. 3662, $\mathrm{n}^{\mathrm{o}} 37$. Olivares manifiesta su desconfianza en una extensa relación que remite al Consejo de Estado: AGS, Estado Italia, leg. 3661, nº 112.

51 Del análisis del concepto de obediencia se ha ocupado VALLADARES RAMÍREZ, 2012. Según la definición que ofrece Covarrubias, vasallo «es el que vive en tierra de algún señor, al qual reconoce y respeta, como a tal; y assí se dixo de vas.dis, en quanto promete ser fiel». COVARRUBIAS OROZCO, 1611: 65r. Sobre el concepto del vasallaje y sus distintos tipos, véase la reflexión de ARANDA PÉREZ, 2012: 57-69.

52 «Yo no estaba obligada pues que yo no tengo la honrra de ser súbdita y nadie me pueda atribuyr a mal de que yo vaya con Monsieur mi marido siendo Dios solo el que me puede separar dél [...]». Copia de la carta de la princesa de Carignano a Olivares, 21 de abril de 1640, AGS, Estado Italia, leg. 3648, no 19.

53 Carta de Felipe IV a la princesa de Carignano, 22 de junio de 1640, Ibidem, $\mathrm{n}^{\circ} 43$.

54 «Obligación, la correspodencia que uno deve tener al beneficio recibido de otro». Cfra. CLAVERO, 1991: 91. Sobre el concepto de merced en relación con el servicio y la obligación 
El valido la acusó asimismo de «desacato» hacia la reina por los incidentes protagonizados con la duquesa de Chevreuse ${ }^{55}$ durante unas fiestas celebradas en febrero de $1638^{56}$. El conflicto se desencadenó cuando ambas presenciaron un juego de sortija: para evitar juntarlas, se colocó a la duquesa en una ventana junto al príncipe heredero Baltasar Carlos, y a María de Borbón en otra con la reina Isabel. Parece que la de Carignano se mostró muy molesta con los agasajos que los monarcas le brindaron a la duquesa y con el tratamiento que se le había otorgado en los actos públicos, hasta tal punto que se fue $\sin$ despedirse de la reina, amenazando con no regresar a palacio ${ }^{57}$. A pesar de los encarecidos intentos del rey por agradar a la princesa dándole un mejor asiento en la corrida de toros siguiente, no consiguió desagraviarla; al contrario: multiplicó sus intenciones de marchar junto a su marido ${ }^{58}$.

Como recientemente ha señalado Valladares, mientras los conceptos de $f i$ delidad y lealtad, sin ser sinónimos, resultan similares, ambos guardan una mayor distancia con respecto al de obediencia ${ }^{59}$. Acabamos de apuntar que la obediencia no era un requisito que los príncipes de Carignano debiesen cumplir, al no ser súbditos ni vasallos de Felipe IV. Sin embargo, en la cláusula de protección sí se esperaba que Tomás - y en adición su esposa e hijosmostrase fidelidad al monarca, algo que infringió al negociar con Francia y

que deriva de ello, nos remitimos al capítulo completo «Contraria Donario: la liberalidad feudal». Consúltese asimismo el estudio de GIL PUJOL, 5 (San Sebastián, 2009): 83-106.

55 Marie-Aimée de Rohan- Montbazon (1600-1679) contrajo matrimonio en primeras nupcias con el duque de Luynes, favorito de Luis XIII. Dama de Ana de Austria, se convirtió en una de sus confidentes hasta que en 1622 fue expulsada de palacio. Regresó a la Corte como duquesa de Chevreuse tras su segundo matrimonio en abril de 1622 con Claude de Lorraine, príncipe de Joinville. DA VINHA, 2009: 160-169. La azarosa vida de la duquesa de Chevreuse ha dado lugar a varias biografías: COUSIN, 1856. BATIFFOL, 1913. POISSON, 1999.

56 Marie de Rohan estuvo en Madrid para tratar en nombre de los monarcas ingleses una posible alianza contra los holandeses y el matrimonio entre Baltasar Carlos y la princesa inglesa María. Le roy d'Espagne au Cardenal-Infante, 13 febrier 1638, AMAE, CP, Espagne, vol. 19 , fols. $7 \mathrm{r}-8 \mathrm{v}$.

57 Según el marqués de Castañeda, la princesa dijo «que en Francia se tenía tan grande respeto a los Príncipes de la Sangre que los reyes no los humillavan tanto como lo hazían los de España y de aquí salió con furia y con lágrimas a dezirme el agravio mayor que havía recivido de V. Magestad y que havía de ser más sensible a su marido, porque hera el Príncipe más estimado en el mundo [...] sin ser milagro podían ser Reyes su marido y su A. y cierto que a mi entender aludió esto al derecho que los Príncipes de la Sangre tienen a la cassa de Francia y que hera muy posible suceder en la cassa de Suison». Consulta del marqués de Castañeda al rey, 7 de junio de 1644, AGS, Estado Italia, leg. 3649.

58 Consulta del Consejo de Estado, AGS, Estado Francia, K-1418, nº 68 a). Los desplantes ante el rey no eran exclusivos de la nobleza francesa: con la llegada al trono de Felipe V parte de la Grandeza española también expresó su descontento. TERRASA LOZANO, 14 (Salamanca, 2013): 163-197.

59 COVARRUBIAS OROZCO, 1611: fol. 400r. 
con la duquesa de Saboya. Ello explica que la actitud del príncipe fuese considerada como felonía: «vocablo antiguo castellano que vale tanto como deslealtad, trayción, alevosía, a fallendo, y assí valdrá tanto como engaño calificado». La inobediencia de la princesa de Carignano, manifestada en sus numerosos intentos de fuga, constituyó una prueba de que el pacto formulado entre el matrimonio y Felipe IV no se encontraba en sus mejores momentos ${ }^{60}$. Las numerosas consultas de estado dedicadas a este suceso dan muestra de la importancia que para la Monarquía representaba Tomás de Carignano. Dado que María de Borbón era el «instrumento» mediante el cual la Corona pretendía asegurar la fidelidad del príncipe, analizaremos a continuación las acusaciones vertidas sobre la francesa con el objeto de invalidar su rol como intermediaria.

\section{El ingrato comportamiento de «la más rara mujer que ha nacido en Francia"}

La actitud de la princesa provocó enormes quebraderos de cabeza a los miembros del Consejo de Estado, quienes, conscientes de la influencia que ejercía sobre su marido, dedicaron múltiples esfuerzos en aras de evitar un conflicto ${ }^{61}$. Especialmente compleja resultó la negociación para el valido, encargado de comunicar a la francesa los continuos aplazamientos de su viaje. Ya a finales de diciembre de 1636 Olivares escribía al rey que:

no se puede fiar de ninguna manera porque ella es loca como Juan de Cárdenas, y es francesa más que el cardenal Richelieu y nos aborrece más que él, y esto lo ha dicho al Rey delante de mí una gran persona, y todas sus criadas enteramente lo dizen a vozes a las damas y dueñas de honor [...] y sabemos que en secreto escribe lo contrario a su marido ${ }^{62}$.

Es esta la primera vez que hemos documentado la referencia a María de Borbón como «loca», si bien no será la última. Consideramos de enorme interés profundizar en este calificativo empleado como manera de invalidar sus argumentos, explicar su comportamiento, así como de justificar el trato que el valido aconsejó brindarle. En junio de 1637, el cardenal-Infante se excusó

60 VALLADARES RAMÍREZ, 2015: 25-28.

${ }^{61}$ La propia princesa reconoció el poder de convicción que tenía sobre su esposo: «si hubiera deseado que dexase el servicio de su Magestad yo hubiera dexado suceder lo que Dios hubiera sido servido [...]». Copia (en español) de la carta de la princesa de Carignano a Olivares, 21 de abril de 1640, AGS, Estado Italia, leg. 3648, nº 19.

62 Consulta del Consejo de Estado, 29 de noviembre de 1636, AGS, Estado Francia, K1418. 
ante Olivares en nombre de Tomás, quien lamentaba «las extravagancias de su mujer, y dize que es una loca, que no haga caso de lo que dice». Al mismo tiempo, el gobernador de Flandes eximía al príncipe de toda culpa ${ }^{63}$, opinión compartida en Madrid, donde siempre se le consideró una víctima de la «dañossa» princesa $^{64}$.

Bethany Aram ha estudiado los usos políticos derivados de la vinculación de locura y feminidad para Juana I de Castilla, que justificaron su reclusión en el castillo de Tordesillas ${ }^{65}$. Si en ese caso la única que salió perjudicada fue la propia reina, despojada del poder por su padre, su marido y posteriormente su hijo, en el estudio que nos ocupa parece que el uso de la locura se realizó por ambas partes. La consideración de María de Borbón como loca hacía referencia a su comportamiento presuntuoso y altivo, algo que la Corona aprovechó para invalidarla como representante del príncipe Tomás en las negociaciones. La princesa había dado muestras de algunas de las definiciones que Covarrubias ofrece en su famoso Tesoro de la lengua, si interpretamos que en los accesos de cólera la francesa perdía momentáneamente el juicio, al no atender a las explicaciones de los enviados del rey cuando le comunicaban un nuevo retraso de su viaje ${ }^{66}$. Las consultas del Consejo de Estado atribuyeron su extravagancia a su condición femenina y a su naturaleza francesa, lo que justificaba - en opinión de Olivares - su incapacidad para tratar sobre negocios ${ }^{67}$. El valido reconocía haber entablado conversaciones con ella en repetidas ocasiones, no pudiendo llegar a un acuerdo debido a su falta de razón y a su cambiante carácter, pues pasaba de las lágrimas a la rabia, los gritos y las amenazas en cuestión de segundos:

63 Carta del principe Thomas al conde duque, 17 de febrero de 1637, Ibidem, $\mathrm{n}^{\circ} 78$.

64 Este fue el parecer al que llegaron los miembros presentes del Consejo de Estado -el marqués de Santa Cruz, el marqués de Villafranca, el conde de Castrillo, el cardenal Borja, Villahermosa y el conde de Oñate- en una consulta realizada el 2 de junio 1638. AHN, Estado, leg. $8607, \mathrm{n}^{\circ} 3$.

65 ARAM, 2004: 73-90; 2001. En la época se consideraba que las mujeres eran más proclives - debido a su inferioridad con respecto al género masculino - a sucumbir a las tentaciones del diablo. Así, por ejemplo, se sospechaba de aquellas que decían presenciar visiones o sueños, como le sucedió a Lucrecia de León. KAGAN, 1991: 137-141. Sobre el concepto de locura, nos remitimos al clásico trabajo de FOUCAULT, 1997 (primera edición 1964).

66 «[...] O puedese haver dicho de locus à luce per contrarium semsum por havérsele ofuscado y entenebrecido el entendimiento». COVARRUBIAS OROZCO, 1611: fol. 527.

67 «Los inconvenientes que tiene el fiárselos bien se ven siendo una muger francesa por naturaleza y por condición mucho más de suma vanidad y extravagancia». Consultas del Consejo de Estado, 23 de septiembre de 1640, AGS, Estado Italia, leg. 3648, $\mathrm{n}^{\circ} 45$ y 46 . En una Relación de lo que ha pasado con la Serenísima Princesa de Cariñán fechada el 14 de febrero de 1640, se hacía referencia a la indiscreción de la francesa «verdaderamente las mugeres aunque sean Princesas, naturalmente son poco reservadas en sus acciones y palabras por naturaleza, cossa diffícil de vencer». AGS, Estado Italia, leg. 3661, nº 115. 
[...] sólo se sirviese Vuestra Magestad de escusarme de que no tratase ningún negocio con esta Princesa, cuya condición es tan terrible que confieso a Vuestra Magestad como cristiano que tengo a milagro de Nuestro Señor evidente no me haver perdido con ella, porque en primer lugar razón ni verdad no tiene lugar con ella ni la entiende ni la haze fuerza, en segundo nada que se assienta con ella tiene firmeza de oras, su vanidad y presumpción es tal que la he oído muchas vezes que es la primera Princesa del mundo y a esta medida es la sobervia y arrozamiento y la desestimación de lo que mas deverá venerar ${ }^{68}$.

María de Borbón creía que su condición femenina era uno de los prejuicios que llevaron a Olivares a evitar considerarla intermediaria de su esposo ${ }^{69}$. Por esta razón, se quejó en su correspondencia del menosprecio sufrido al ser sustituida por el conde de Boeto — agente de Tomás y Mauricio en Madrid ${ }^{70}$-; un motivo más que — según ella - hacía comprensible y necesaria su salida de la Corte ${ }^{71}$. Sea como fuere, a la Monarquía le interesaba propagar un discurso que invalidase las acusaciones públicas que la de Carignano había diseminado fuera de las fronteras españolas, asegurando que ya había escrito varios manifiestos narrando las humillaciones recibidas ${ }^{72}$.

A juzgar por las misivas en las que Tomás daba cuenta de estar al tanto del comportamiento de su esposa, consideramos muy posible que ambos jugasen con este calificativo, evitando así un posible castigo por parte del rey ${ }^{73}$. Tal y como Magdalena Sánchez ha señalado para el caso de las mujeres Habsburgo, era habitual que éstas aludiesen a una supuesta enfermedad — que solía ser melancolía - en aras de justificar acciones que se salían de lo socialmente establecido $^{74}$. La princesa de Carignano incidirá asimismo en su mala condi-

68 Papel del conde duque sobre la plática que tuvo con la princesa, 13 de abril de 1640, AGS, Estado, leg. 3648, $n^{\circ} 5$.

69 AGS, Estado Italia, leg. $3661, n^{\circ} 175$, s.f.

70 Lettere di Tommaso alla principessa di Carignano, 15 agosto 1639. ASTo, Lettere Principi Diversi, Savoia-Carignano, mazzo 53. Tomás le confiesa a su mujer que el duque de Longueville le había asegurado que la corona francesa cumpliría todas sus promesas si abandonaban el servicio a Felipe IV.

${ }_{71}$ Carta de la princesa de Carignano al conde duque, 3 de marzo de 1640, AGS, Estado Italia, leg. $3661, \mathrm{n}^{\mathrm{o}} 67$.

72 La princesa tenía intención de dar a conocer «la sin razón y violencia que padece en pago de lo que ha servido su marido y de haver perdido al señor conde de Suason su hermano en servicio desta Corona». Parecer de la Junta, 23 de marzo de 1642, AGS, Estado Italia, leg. 3847, $\mathrm{n}^{\circ} 76$.

73 El Consejo de Estado trataba ya a mediados del mes de diciembre de 1637 una consulta relativa a que se le comunicase a Tomás que por vía de su mujer las negociaciones no eran viables. Carta de Andrés de Rozas a Pedro de Arze, 15 de diciembre de 1637, AGS, Estado Italia, leg. $3661, \mathrm{n}^{\mathrm{o}} 1$.

74 SÁNCHEZ, 1998: 158-159. El capítulo siete, «Melancholy and Infirmity», está dedicado al uso político que la emperatriz María, su hija sor Margarita de Cruz y la reina Margarita de Austria hicieron de sus enfermedades para que Felipe III las visitase más a menudo. 
ción física para que Felipe IV le permitiese regresar con su marido ${ }^{75}$. Lo que quizá no esperaba es que el monarca empleara el mismo recurso para justificar el retraso de su partida, aludiendo a la obligación que tenía de confirmar la seguridad de su viaje para prevenir su salud y la de sus hijos ${ }^{76}$. De hecho, cuando durante el gobierno de la reina Isabel de Borbón (1642-1644) una Junta trató sobre la conveniencia de trasladar a la princesa a palacio o a otro lugar, Olivares recomendó aprovechar el temor que la francesa tenía a morir para conseguir que acatase la disposición regia ${ }^{77}$.

María de Borbón no fue la única que se escudó en sus problemas de salud para reclamar el regreso prometido a tierras italianas. Margarita de Saboya, la que fuera virreina de Portugal y hermana de Tomás recurrió al mismo argumento en idéntica cronología ${ }^{78}$. Margarita escribió durante años al monarca solicitando que le permitiese volver a Mantua para estar con su hija, tal y como Felipe IV le había prometido al ofrecerle el virreinato de Portugal ${ }^{79}$. Después del levantamiento portugués en 1640, Margarita partió hacia Madrid con el propósito de visitar al rey. Para su sorpresa, fue detenida en Mérida siete meses, tras los cuales Felipe IV ordenó que se instalase en Ocaña, donde permaneció un largo período hasta que a comienzos de 1643 fue alojada en las Descalzas Reales ${ }^{80}$. Durante su estancia castellana tomó en numerosas ocasiones la pluma para recordarle a su primo su deseo de regresar a Italia, así como el servicio que siempre le había prestado ${ }^{81}$, apelando a su avanzada edad y a su mala

75 «[...] suplicándole disponga que yo vea prontamente los efetos dellos porque mi salud no me deja esperar larga vida y por no poder estar más tiempo de la manera que estoy». Carta de Felipe IV a la princesa de Carignano, 7 de agosto de 1641, AGS, Estado Italia, leg. 3847, $\mathrm{n}^{\circ} 102$.

76 Consulta de Estado, 23 de julio de 1641, AGS, Estado Italia, leg. 3648, no 110; Carta de la princesa de Carignano a Felipe IV, 20 de mayo de 1642, AGS, Estado, Italia, leg. 3853, $\mathrm{n}^{\circ} 239$.

77 «...y llegando el tiempo de los calores ella misma ynstará para mudar de residencia, y abrazará quizá lo que aora rehusa, porque aseguran los que la conocen bien que tiene mucho miedo a la muerte y que si enfermase por poco que sea ella no persistirá donde se halla». $P a$ recer del conde duque de Olivares, 26 de abril de 1642, AGS, Estado Italia, leg. 3847, $\mathrm{n}^{\circ} 80$.

78 La figura de Margarita ha suscitado recientemente el interés de diversos investigadores, tras muchos años en el olvido después de la biografía que le dedicara QUAZZA, 1930, impregnada de un fuerte sentimiento antiespañol. Véanse los estudios de SCHAUB, 2001 y RAVIOLA, 2012; 2013.

79 «No es en lo que menos muestro al mundo lo que estimo vuestra persona, con encomendaros uno de los goviernos de España de personas reales [...] para que mientras las cosas están turbadas en Italia, tengáis ocupación fuera de ella por estos dos años por no apartaros más tiempo de vuestra hija, en el que parece que se compondrán las cosas, para que podáis vivir en su compañía con el gusto que deseo». AGS, Estado Portugal, leg. 4045, n 1 .

80 Consulta del Consejo de Estado, 15 de enero de 1643, Ibidem, $\mathrm{n}^{\circ} 24$. Margarita se alojó en el convento de la Encarnación hasta que en julio le habilitaron un cuarto en las Descalzas. PELLICER DE OSSAU Y TOVAR, 1644: fols. 147v-148r, BNE, Mss. 7693.

81 «Yo vine a España obedecer a V.M. que se sirvió de mostrar que le sería de gusto el verme para ampararme y procurarme todo consuelo y satisfación en mis interesses, i jamás 
salud. Margarita fallecería en Burgos en 1655, sin haber logrado su deseo de retornar a la península italiana, algo que sí conseguiría María de Borbón ${ }^{82}$.

\section{CONCLUSIONES}

Tal y como unos años después haría el gran príncipe de Condé Luis de Borbón ${ }^{83}$, Tomás de Saboya - y por extensión, su familia - abrazó el servicio a Felipe IV mediante un tratado de protección, pues su condición de extranjero exigía establecer los términos a partir de los cuales estarían vinculados con la Monarquía Hispánica. Esta relación de servicio se basaba en la reciprocidad y en la fidelidad que ambas partes debían mostrar, de la que se esperaban una serie de acciones ${ }^{84}$. Por supuesto, este intercambio debía ser beneficioso para ambas partes, y en consecuencia, debía consensuarse mediante la negociación, tal y como había sucedido. El de Carignano ofreció su servicio al monarca católico por discrepar del gobierno de su hermano Víctor Amadeo y posteriormente del de su cuñada - cuya legitimidad como regente cuestionaba-, lo cual no fue sin embargo seguido de una desnaturalización ${ }^{85}$. María de Borbón nació siendo súbdita de Luis XIII, pero al contraer matrimonio pasó a serlo de Saboya —al igual que su marido-, convirtiéndose además en titular de un principado en el Piamonte. A esto debemos añadir el parentesco que doblemente les unía a los soberanos: él era primo hermano de Felipe IV; ella prima segunda de Isabel de Borbón, lo que comportaba un ingrediente de fidelidad familiar a tener en cuenta.

Pese a la libertad de ambas partes a la hora de establecer este acuerdo, no debemos olvidar que no se trataba de una relación entre iguales. De hecho, el conflicto comienza en el momento en el que la parte más débil - esto es, la representada por el príncipe de Carignano- pretende rescindir el pacto. En realidad, el de Saboya fue el primero en incumplir una de las cláusulas firmadas, a saber: la que le impedía establecer ligas o confederaciones con los enemigos de la Monarquía, pues había estado negociando con Francia y con la duquesa de Saboya. Por su parte, Tomás se escudó en que previamente el rey no le había otorgado lo

pensé de haberme de apartar de los ojos de V.M. sino para servirle o volver a Italia». Carta de Margarita de Saboya a Felipe IV, 10 de julio de 1642, AGS, Estado España, leg. 2666.

82 «Mis años, mi poca salud y mis achaques son tales que no pueden sufrir aires tan recios y continuos como los de Ocaña, lo que requieren es descanso y consuelo [...] suplico con toda humildad, y veneración me haga merced y favor en quanto no permite de volber a Italia de no apartarme dellos». AGS, Estado Portugal, leg. 4045, nº 23.

83 Nos remitimos al estudio de BËGUIN, 1999.

84 Sobre el significado del servicio en la Monarquía Hispánica, véase a la reflexión que ofrece ESTEBAN ESTRÍNGANA, 2012: 11-15.

85 RUIZ IBÁÑEZ, 2012: 168. 
prometido, lo que le facultaba a dar el servicio por finalizado. La Corona no podía permitir el paso del príncipe a las filas enemigas, por lo que intentó que regresase a la protección del Rey Católico en una operación en la cual la permanencia de la princesa en Madrid resultaba clave. Pero, ¿podía Felipe IV retener a María de Borbón en contra de su voluntad? Esta cuestión se había planteado en diversas ocasiones en las sesiones del Consejo de Estado. En opinión de Olivares, si bien consideraba «no ser justo ni en conciencia ni en razón humana el detener a su Alteza», debido a la «condición de esta señora y el malo y perverso affecto que se reconoce en ella», era partidario de que se retrasase la respuesta, sin llegar a negarle nunca el reunirse con su marido ${ }^{86}$.

No será hasta después de 1642, una vez que Tomás había firmado la paz con la duquesa regente y pasó al servicio de Francia, cuando se consideró por primera vez a la princesa y a sus hijos «prisioneros por la felonía del Príncipe» ${ }^{87}$. Como ya hemos señalado, Tomás aparece a lo largo del proceso exento de toda culpa, la cual recayó irremisiblemente en María de Borbón, artífice de la manipulación del juicio de su esposo. Creemos que la voluntad por exculpar al príncipe respondía a la necesidad que la Monarquía tenía de un militar experimentado, más que a un prejuicio sobre la naturaleza francesa y la condición femenina de la princesa. Sin entrar a dilucidar si María de Borbón manipuló a su marido en base a su simpatía hacía la corona francesa, nos interesa señalar que la comunicación epistolar intercambiada entre la pareja prueba que Tomás tenía conocimiento de las acciones protagonizadas por su esposa. Ello nos lleva a pensar que el comportamiento de la princesa constituyó un intento por provocar la ruptura con Felipe IV, hipótesis que cobra fuerza si atendemos a las exageradas y constantes demandas de la francesa. Es lógico deducir que Felipe IV no las aceptaría como así sucedió, lo que habilitaría a la pareja a rescindir su servicio - cuyo uso podía ser múltiple, flexible y circunstancial ${ }^{88}$ - y cuya duración estaba condicionada por el interés de ambas partes ${ }^{89}$. A finales de la década de 1630, los príncipes de Carignano consideraron más favorable a sus propios intereses aquello que les ofrecía Francia, lo que derivó en un deservicio a la Monarquía y su consecuente ruptura ${ }^{90}$, tal y como Felipe IV reconoció:

Señora Prima, habiendo entendido que sobre haveros hecho dezir mi voluntad en quanto a vuestra jornada por el conde duque por escrito diferentes vezes tenéis

86 AGS, Estado Italia, leg. 3661, no 112 , fols. 3r y 3v.

87 Consulta del Consejo de Estado, 22 de octubre de 1642, AGS, Estado, leg. 3847, no 285.

88 Las circunstancias según las cuales la nobleza podía cambiar el servicio a un príncipe extranjero aparecen detalladas en RUIZ IBÁÑEZ, 2012: 165-171.

89 THOMPSON, 2012: 283.

90 «La razón de estado aceptó y fomentó que los vasallos fueran fieles al príncipe «por interés, no por amor o amistad», sin importar siquiera la familia». Cfra. VALLADARES RAMÍREZ, 2015: 28. 
resolución de intentarla, he resuelto deciros de mi propia mano que esto será deservicio del Príncipe Thomas mi primo, con lo qual no quedaréis con duda de que me hallo obligado a poner todo embarazo para que no se execute nada que genere desconveniencia y contra la protección en que tengo a mi Primo y a vos y a los Príncipes vuestros hijos por la que firmé y por la que también ha firmado el Príncipe que está en mi poder ${ }^{91}$.

Las excepcionales circunstancias por las que atravesó la Monarquía entre finales de la década de 1630 y comienzos de la siguiente influyeron de manera determinante en la relación que la Corona desarrolló con los príncipes italianos en general, y con los de Carignano en particular. En este sentido, es interesante resaltar la desconfianza que el gobierno de Felipe IV mostró hacia el comportamiento de antiguos servidores de los que se sospechaba que podían actuar en contra de la estabilidad de la Corona, como fue el caso de María de Borbón o de su cuñada Margarita de Saboya.

Como resultado, la Monarquía Hispánica fue flexible a la hora de negociar con estos antiguos servidores que habían faltado a su deber, a los que decidió perdonar intentando reintegrarlos a su servicio. La proliferación en los últimos años de congresos y volúmenes interesados en el análisis del concepto del servicio y la fidelidad al monarca nos ha permitido analizar cómo los príncipes de Carignano forzaron los límites que fijaban —en la teoría- la relación de servicio con el rey. Aprovechándose de la compleja situación en la que se hallaba la monarquía de Felipe IV, estos militares experimentados mantuvieron una actitud abierta frente a las dos coronas más importantes del momento - la francesa y la española-, como fue también el caso del duque de Parma Odoardo Farnese ${ }^{92}$. Asimismo, el caso de estudio elegido pone de manifiesto el daño que las sublevaciones de los súbditos rebeldes portugueses y catalanes habían causado en Madrid. Dichos acontecimientos generaron temor y desconfianza hacia aquellos que hasta entonces se habían mostrado fieles a la Corona, como fueron los hermanos Tomás, Mauricio y Margarita de Saboya, quienes habían heredado de su madre una inclinación favorable a la Monarquía Hispánica ${ }^{93}$. Durante un breve pero intenso período, el príncipe de Carignano ocupó el lugar que su hermano mayor Emanuele Filiberto había dejado vacante tras su muerte en 1624 como importante militar al servicio de la Monarquía Española, demostrando así la impronta pro-española de su ma-

91 Carta de Felipe IV a la princesa de Carignano, 22 de junio de 1640, AGS, Estado Italia, leg. $3648, n^{\circ} 43$.

92 HANLON, 2014.

93 Pese a la política de Carlos Manuel I, la mayor parte de sus hijos mostraron — si no siempre, al menos durante un período de su vida - una inclinación hacia sus raíces españolas, como fue el caso de Manuel Filiberto de Saboya o Maria Apollonia. RAVIOLA, 1 (Madrid, 2014): 257-258. 
dre y la mayoría de sus hermanos ${ }^{94}$. Partiendo de las tradicionales fórmulas políticas plasmadas en los discursos teóricos que hablaban de servicio, lealtad y fidelidad, el matrimonio bien avenido que conformaron los príncipes de Carignano arriesgó y consiguió sacar provecho en la práctica de la delicada situación en la que se encontraba la Monarquía Hispánica en las décadas centrales de la primera mitad del Seiscientos.

\section{BIBLIOGRAFÍA}

Aram, Bethany, «Representing Madness: Text, Gender and Authority in Early Habsburg Spain», in Vicente, Marta, and Corteguera, Luis (eds.), Women, Texts and Authority in the Early Modern Spanish World, Aldershot, Ashgate Publishing, 2004; 73-90.

Aram, Bethany, La reina Juana. Gobierno, piedad y dinastía, Madrid, Marcial Pons, 2001.

Aranda Pérez, Francisco J., «Servir a quién, en qué y cómo: vasallos en la política hispánica moderna", en Esteban Estríngana, Alicia, Servir al rey en la Monarquía de los Austrias. Medios, fines y logros del servicio al soberano en los siglos XVI y XVII, Madrid, Sílex, 2012; 49-84.

Batiffol, Louis, La duchesse de Chevreuse, París, Hachette, 1913.

Béguin, Katia, Les princes de Condé. Rebelles, courtisans et mécènes dans la France du Grand Siècle, Seyssel, Champ Vallon, 1999.

Bély, Lucien, «La Savoie entre Bourbons et Habsbourgs», en La Savoie dans l'Europe. Actes du XXXVIII Congrès des sociétés savantes de Savoie (Moûtiers, 9 et 10 septembre 2000), Moûtiers, 2002.

Caro de Mallén, Ana, Contexto de las reales fiestas que se hizieron en el palacio del buen retiro a la coronación de Rey de Romanos y entrada en Madrid de la señora princesa de Cariñan, Madrid, en la Imprenta del Reyno año 1637.

Claretta, G., Storia della Regenza di Cristina di Francia, Duchessa di Savoia, 16371663. Con annotazioni e documenti inediti. Turín, 1869.

Clavero, Bartolomé, Antidora. Antropología católica de la economía moderna, Milano, Giuffreè Editore, 1991.

Cousin, Víctor, Madame de Chevreuse, París, Didier, 1856.

Covarrubias Orozco, Sebastián de, Tesoro de la Lengua castellana o española, Madrid, 1611.

Da Vinha, Mathieu, «La Casa de Austria», en Grell, Chantal (Dir.), Ana de Austria. Infanta de España y Reina de Francia, Madrid-Versalles, Centro de Estudios Europa hispánica, Centre de Recherche du Château de Versailles, 2009; 155-186.

Dubost, Jean-François, Marie de Médicis. La reina dévoilée, París, Biographie Payot, 2011.

Esteban Estríngana, Alicia, «El servicio: paradigma de relación política en los siglos XVI y XVII», en Esteban Estríngana, Alicia, Servir al rey en la Monarquía de

94 OSBORNE, 2002: 240. 
los Austrias. Medios, fines y logros del servicio al soberano en los siglos XVI y XVII, Madrid, Sílex, 2012; 11-45.

Esteban Estríngana, Alicia, «Los estados de Flandes en el futuro político de los infantes. La designación del Cardenal Infante don Fernando para la lugartenencia Real de Bruselas», en Martínez Millán, José, y Hortal Muñoz, José Eloy (dirs.), La Corte de Felipe IV (1621-1665): reconfiguración de la Monarquía Católica, t. 1, vol. III, 2015; 1615-1678.

Ferretti, Giuliano (dir.), «Christine de France et son siècle», monográfico de la revista Dixseptième siècle, 262/1 (París, 2014): 3-192.

Ferretti, Giuliano (dir.), De Paris à Turin. Christine de France duchesse de Savoie, Grenoble, L'Harmattan, 2014.

Foucault, Michel, Historia de la locura en la época clásica, Méjico, Fondo de Cultura Económica, 1997.

Gil Pujol, Xavier, «The Law of a Good Vassal: Fidelity, Obedience and Obligation in Habsburg Spain», en Arrieta, Jon, y Elliott, John H. (eds.), Forms of Union: the British and Spanish Monarchies in the Seventeenth and Eignteenth Centuries, monográfico de la Revista Internacional de Estudios Vascos-RIEV, 5 (San Sebastián, 2009); 83-106.

Ginarte González, Ventura, «Instrucciones al conde de la Roca para la embajada extraordinaria en Saboya y ordinaria en Venecia», Hispania, 49/172 (Madrid, 1989): 733-752.

Hanlon, Gregory, The Hero of Italy: Odoardo Farnese Duke of Parma, his Soldiers, and his Subjects in the Thirty Years' War, Oxford, Oxford University Press, 2014.

Kagan, Richard L., Los sueños de Lucrecia. Política y profecía en la España del siglo XVI, Madrid, Nerea, 1991.

Masoero, Mariarosa; Mamino, Sergio e Rosso, Claudio (a cura di), Politica e cultura nell'età di Carlo Emanuele I. Torino, Parigi, Madrid, Convegno Internazionale di Studi, Torino 21-24 febbraio 1995, Firenze, Leo S. Olschki, 1999.

Méndez Silva, Rodrigo, Diálogo compendioso de la Antigüedad y cosas memorables de la noble y coronada villa de Madrid y recibimiento que en ella hizo su Magestad Católica con la grandeza de su Corte a la Princesa de Cariñán, claríssima consorte del Sereníssimo Príncipe Tomás, con sus genealogías, Madrid, 1637.

Merlin, Pierpaolo, Tra guerre e tornei. La corte sabauda nell'età di Carlo Emanuele I, Turín, Società Editrice Internacionale, 1991.

Merlotti, Andrea, «Disciplinamento e contrattazione. Dinastia, nobiltà e corte nel Piemonte sabaudo da Carlo II alla guerra civile», in Bianchi, Paola; Gentile, Luisa Clotilde (a cura di), L'affermarsi della corte sabauda: dinastie, poteri, élites in Piemonte e Savoia fra tardo medioevo e prima età moderna, Torino, S. Zamorani, 2006; 227-284.

Oresko, Robert, «Princesses in power and European dynasticism: Marie-Christine of France and Navarre and Maria Giovanna Battista of Savoy-Genevois-Nemours, the last regents of the house of Savoy in their international context», Varallo, Franca (a cura di), In assenza del Re. Le reggenti dal XIV al XVII secolo (Piemonte ed Europa), Firenze, Olschki Editore, 2008; 393-441. 
Oresko, Robert, «The House of Savoy in search for a royal crown in the seventeenth century», in Oresko, Robert; Gibbs, G.C. and Scott, H. M., (eds.) Royal and Republican sovereignity in Early Modern Europe, Cambridge, Cambridge University Press, 1997; 287-294.

Osborne, Toby, Dynasty and diplomacy in the court of Savoy. Political culture and the Thirty years' war, Cambridge, Cambridge University Press, 2002.

Parrott, David, «A prince souverain and the French crown: Charles de Nevers, 15801637», in Oresko, Robert; Gibbs, G.C. and Scott, H. M., (eds.) Royal and Republican sovereignity in Early Modern Europe, Cambridge, Cambridge University Press, 1997; 149-187.

Patrucco, Carlo, La duchessa di Savoia e il Principe Tomaso di Carignano durante la guerra civile in Piemonte (1637-1642), Pinerolo, Tipografia Sociale, 1898.

Pellicer de Ossau y Tovar, José, Avisos históricos que comprenden las noticias y sucesos más particulares ocurridos en nuestra Monarquía desde 7 de enero de 1642 a 25 de octubre de 1644.

Picco, Leila, Il Savoia sordomuto. Emanuele Filiberto di Savoia Carignano 16281709, Torino, G. Giappichelli Editore, 2010.

Poisson, George, La Duquesa de Chevreuse, París, Perrin, 1999.

Quazza, Guido, Guerra civile in Piemonte, 1637-1642, nuove ricerche, Torino, Deputazione subalpina di Storia Patria, 1960.

Quazza, Romolo, Margherita Di Savoia. Duchessa di Mantova e Vice-regina del Portogallo (1589-1655), Torino, G. B. Paravia, 1930.

Quazza, Romolo, Tommaso di Savoia-Carignano nelle champagne di Fiandra e di Francia, 1635-1638, pagine di storia europea diplomática e militare (da documenti inediti), Torino SEI Stampa, 1941.

Raviola, Blythe Alice, «“A fatal máquina”. Margarida de Sabóia (1598-1656), duquesa de Mântua e vice-rainha de Portugal», en Raviola, Blythe Alice, y Lopes, M. A., Portugal e o Piemonte. A Casa Real portuguesa e os Sabóias entre interesses dinásticos, relações internacionais e destinos políticos (sécs. XII-XX), Universidade de Coimbra, Coimbra, 2012; 133-166.

Raviola, Blythe Alice, «"En el Real serbicio de Vuestra Majestad”. El cardenal Mauricio de Saboya entre Turín, Roma, Madrid y París», La doble lealtad: entre el servicio al rey y la obligación a la iglesia. Libros de la Corte, 1 (Madrid, 2014): pp. 244-259.

Raviola, Blythe Alice, «The three Lives of Margherita of Savoy-Gonzaga, Duchess of Mantua and Vicereine of Portugal», in Cruz, Anne J., and Stampino, Maria Galli, Early Modern Habsburg Women. Transnational Contexts, Cultural Conflicts, Dynastic Continuities, Farnham/Burlington, Ashgate, 2013; 58-76.

Rosso, Claudio, «Le due Cristine: Madame Reale fra agiografia e legenda nera», Varallo, Franca (a cura di), In assenza del Re. Le reggenti dal XIV al XVII secolo (Piemonte ed Europa), Firenze, Olschki Editore, 2008; 367-392. 
Rosso, Claudio, «Uomini e poteri nella Torino barocca (1630-1675)», Ricuperati, Giuseppe (a cura di), La città fra crisi e ripresa (1630-1730), Torino, Giulio Einaudi editore, 2002; 116-162.

Ruiz Ibáñez, José Javier, «Servir a un rey extraño. La nobleza francesa y la élite municipal en sus alianzas con el Rey Católico en el siglo XVI», en Esteban Estríngana, Alicia, Servir al rey en la Monarquía de los Austrias. Medios, fines y logros del servicio al soberano en los siglos XVI y XVII, Madrid, Sílex, 2012; 165-189.

Sánchez de Espejo, Andrés, Diálogo Relación ajustada en lo possible a la verdad y repartida en dos discursos. El primero, de la entrada en estos reynos de Madama María de Borbón, Princesa de Cariñán. El segundo, de las fiestas que se celebraron en el Real Palacio del Buen Retiro a la elección del Rey de Romanos, Madrid, 1637.

Sánchez, Magdalena, The Empress, the Queen, and the Nun. Women and power at the Court of Philip III of Spain, Baltimore, The Johns Hopkins University Press, 1998.

Schaub, Jean-Frédéric, Le Portugal au temps du comte-duc d'Olivares (1621-1640). Le conflict de juridictions comme exercice de la politique, Madrid, Casa de Velázquez, 2001.

Sclopis, Federigo, Documenti ragguardanti alla storia della vita di Tommaso Fancesco di Savoia príncipe di Carignano, Torino, 1832.

Spagnoletti, Angelantonio, «Tommaso di Savoia: un principe cadetto nel giocco della potenze europee della prima metà del Seicento», en Chauvard, Jean-François; Merlotti; e Visceglia, Maria Antonietta (a cura di), Casa di Savoia e Curia romana dal Cinquecento al Risorgimento, Roma, École Française de Rome, 2015; 231-258.

Terrasa Lozano, Antonio, «El asunto del banquillo de 1705 y la oposición de la Grandeza a las mudanzas borbónicas: de la anécdota a la defensa del cuerpo místico de la Monarquía», Cuadernos dieciochistas, 14 (Salamanca, 2013); 163-197.

Thompson, Irving A.A., «Do ut des: la economía política del «servicio» en la Castilla moderna», en Esteban Estríngana, Alicia, Servir al rey en la Monarquía de los Austrias. Medios, fines y logros del servicio al soberano en los siglos XVI y XVII, Madrid, Sílex, 2012; 283-296.

Valladares Ramírez, Rafael, «El problema de la obediencia en la Monaquía Hispánica», en Esteban Estríngana Alicia, Servir al rey en la Monarquía de los Austrias. Medios, fines y logros del servicio al soberano en los siglos XVI y XVII, Madrid, Sílex, 2012; 121-145.

Valladares Ramírez, Rafael, «Fidelidad, lealtad y obediencia. Tres conceptos en la Monarquía de los Austrias», en Quirós Rosado, Roberto y Bravo Lozano, Cristina (eds.), Los hilos de Penélope. Lealtad y fidelidades en la Monarquía de Espa$\tilde{n} a, 1648-1714$, Valencia, Albatros Editores, 2015; 21-38.

Recibido: $16 / 10 / 2015$

Aceptado: 29/04/2016 